\title{
Aprendizagens Docentes no Contexto da Resolução de Problemas
}

\author{
Teaching Learnings in the Context of Problem Solving
}

\author{
Andresa Maria Justulin*a; Lourdes de La Rosa Onuchic ${ }^{b}$ \\ ${ }^{a}$ Universidade Tecnológica Federal do Paraná, Programa de Pós-Graduação Stricto Sensu em Ensino de Matemática, PR, Brasil. \\ bUniversidade Estadual Paulista "Julio de Mesquita Filho". SP, Brasil. \\ *E-mail: ajustulin@utfpr.edu.br
}

\begin{abstract}
Resumo
O presente trabalho teve como objetivo investigar aprendizagens profissionais docentes que se manifestam em um grupo de estudo apoiado na Metodologia de Ensino-Aprendizagem-Avaliação de Matemática através da Resolução de Problemas. Os participantes da pesquisa foram sete professores de Matemática, em exercício, de uma escola estadual. A pesquisa, de caráter qualitativo, utilizou a observação participante e para a coleta de dados foram considerados os registros escritos e em áudio e vídeo oriundos das gravações dos encontros. Para análise dos dados foram construídos quatro eixos temáticos: A Resolução de Problemas na aprendizagem e na ressignificação dos conhecimentos matemático e didático-pedagógico na formação do professor de Matemática; a Problematização da Resolução de Problemas nas práticas de aprender e ensinar Matemática na sala de aula; a Metodologia de Ensino-Aprendizagem-Avaliação de Matemática através da Resolução de Problemas na formação do professor de Matemática; os grupos de estudo sobre Resolução de Problemas como espaços de aprendizagem de professores e de futuros professores. Os resultados indicaram que a referida Metodologia, trabalhada nos grupos de estudo, possibilitou a mobilização do conhecimento matemático dos participantes ao trabalhar os problemas, bem como a mobilização de saberes didático-pedagógicos, ao refletir sobre suas experiências de sala de aula. Esses saberes explicitaram que as aprendizagens profissionais docentes se relacionaram aos aspectos teóricos, didáticos e metodológicos referentes aos conteúdos matemáticos trabalhados e, também, à visão de escola, de mundo e de sujeito que se pretende formar.
\end{abstract}

Palavras-chave: Formação de Professores. Grupos de Estudo. Resolução de Problemas. Educação Matemática.

\begin{abstract}
The teacher training, in many cases, has been occurred by courses focused on the discipline content and disconnected from the school reality. New proposals that values training in the teacher's workplace and the classroom reality are possible. This paper aimed at investigating teachers ' professional learnings that manifest in a study group supported in the Methodology of Teaching-Learning-Evaluation of Mathematics through Problem Solving. The participants of the research were seven acting teachers of Mathematics from a school of the state of São Paulo, Brazil. The research, in qualitative character, used the participating observation, and written records and audio and video recordings from the meetings were considered for data collection. Four thematic axes were built for data analysis. Problem Solving in learning and in the resignification of mathematical and didactic-pedagogical knowledges in the training of Mathematics teachers; Problematization of Problem Solving in learning and teaching practices in classroom; Methodology of Teaching-Learning-Evaluation of Mathematics through Problem Solving in the training of the teacher of Mathematics; the study groups on Problem Solving as learning spaces of teachers and future teachers. The results indicated that the referred Methodology, worked in the study groups, enabled the mobilization of the participants' mathematical knowledges by working the problems, as well as the mobilization of didactic and pedagogical knowledges, by thinking over their experiences in classroom. Such knowledges explained that teacher professional learnings relate to the theoretical, didactic and methodological aspects regarding the mathematical contents worked, and also the view of school, world and subject intending to educate.
\end{abstract}

Keywords: Teacher Training. Problem Solving. Mathematic Education.

\section{Introdução}

A formação de professores, por si só, é um tema relevante e desafiador. No Brasil, apesar de as discussões e pesquisas indicarem possibilidades e a real necessidade de ações por parte das políticas públicas e da sociedade, a implementação de propostas ainda se encontra na esfera do desejado. Algumas perspectivas de formação a tempo difundidas consideram a necessidade do ensino de conteúdo e de técnicas aos professores para aplicação em suas salas de aula.

Na contramão a esse olhar, pode-se pensar uma formação de professores voltada ao desenvolvimento profissional, ao locus de trabalho do docente, em uma aprendizagem situada no interior da escola e mediada pelos demais colegas de profissão. De acordo com Ponte (1998), nessa perspectiva o movimento é de "dentro para fora", ao contrário do que acontece em cursos tradicionais de formação, onde os professores recebem sua formação em um movimento de "fora para dentro". À luz desse referencial, a pesquisadora convidou seus colegas professores de Matemática para constituir um grupo de estudo na escola.

$\mathrm{Na}$ rede escolar do estado de São Paulo, Brasil, há um 
tempo de trabalho coletivo semanal, que varia de acordo com a carga horária de aulas do professor (entre uma ou três), em que todos os docentes se reúnem para discutir aspectos escolares relacionados à escola e com potencial formativo. Esse momento é chamado de Aula de Trabalho Pedagógico Coletivo (ATPC) e foi o espaço em que a presente pesquisa foi desenvolvida em um grupo composto por sete professores de Matemática.

Outro tema relevante e desafiador ao professor de Matemática é a resolução de problemas e sua abordagem enquanto metodologia de ensino. É comum os professores afirmarem que fazem uso de problemas em suas aulas, mas conforme Schroeder e Lester (1989), há diferentes abordagens. No Brasil, apesar de recomendada por diferentes documentos oficiais, a Resolução de Problemas entendida como Metodologia de Ensino de Matemática ainda apresenta limitações, por parte do professor de Matemática, ao ser implementada em sala de aula (Morais \& Justulin, 2016).

Nessa esteira, como contexto para os estudos do grupo, a Metodologia de Ensino-Aprendizagem-Avaliação de Matemática através da Resolução de Problemas (Onuchic, 1999, Onuchic \& Allevato, 2011, 2014) pode ser vista como um caminho para o professor mediar a construção de conhecimentos por parte de seus alunos. Por meio desta Metodologia, o aluno deve ser visto como um construtor ativo de seus conhecimentos. O professor deve selecionar um problema para sua turma, que possa fazê-los partir do que já conhecem e relacionar esse conhecimento para resolvêlo. Esse trabalho, em sala de aula, deve ser promovido em grupos. A partir da discussão, das resoluções elaboradas pelos grupos durante a plenária, o professor deve instigar seus alunos à busca por um consenso e, em seguida, deve fazer a formalização do conteúdo matemático construído.

Esses pressupostos para utilização da resolução de problemas em sala de aula também podem ser explorados na formação de professores e, assim, com base nas ideias apresentadas, foi elaborada a pergunta norteadora da pesquisa: "Que aprendizagens profissionais docentes se manifestam em um grupo de estudo apoiado na Metodologia de Ensino-Aprendizagem-Avaliação de Matemática através da Resolução de Problemas?”

Ao tratar de formação de professores de Matemática, faz-se necessário esclarecer o que se entende sobre saber docente, visto que é ele quem pode revelar aprendizagens, transformações e desenvolvimento profissional. Para tanto, este texto apoiar-se-á em Tardif(2010, p. 36) para o qual o saber docente é "um saber plural, formado pelo amálgama, mais ou menos coerente, de saberes oriundos da formação profissional e de saberes disciplinares, curriculares e experienciais".

O referido autor esclarece, ainda, que a noção de "saber", para ele, "engloba os conhecimentos, as competências, as habilidades (ou aptidões) e as atitudes, isto é, aquilo que muitas vezes foi chamado de saber, saber-fazer e saber-ser."
(Tardif, 2010, p.255).

Tardif (2020) estabelece, ainda, diversas categorias de saberes docente e suas origens, que seriam:

1) Saberes da formação profissional: relacionam-se ao conjunto de saberes transmitidos pelas instituições de ensino de formação de professores (Universidades). Também fazem parte desta categoria as doutrinas pedagógicas ou concepções sobre o ensino, que acabam orientando a prática pedagógica do professor;

2) Saberes disciplinares: referem-se à disciplina de ensino e são transmitidos pelas universidades através da formação (inicial e contínua) dos professores;

3) Saberes curriculares: referem-se aos saberes sociais definidos e selecionados pela escola como modelos e necessários para a formação da cultura erudita;

4) Saberes experienciais: são desenvolvidos por meio da experiência docente e validados por ela. "Eles incorporam-se à experiência individual e coletiva sob a forma de habitus e de habilidades, de saber-fazer e saberser." (Tardif, 2010, p.39).

Ao contrastar os cursos de formação oferecidos nas modalidades de treinamento e capacitação e os espaços de formação que possibilitam o desenvolvimento profissional de professores, Ponte (1998) indicou diferenças entre eles. Na formação pressupõe-se que o professor, ao frequentar cursos e palestras, receba teorias, em um movimento de fora para dentro, enquanto que, no desenvolvimento profissional o movimento é inverso, ou seja, de dentro para fora, considerando teoria e prática de forma interligada. No entanto, o autor destaca ainda que a formação pode ser utilizada de modo a favorecer o desenvolvimento profissional. Nesse sentido, "o professor que quer se desenvolver plenamente tem toda a vantagem em tirar partido das oportunidades de formação que correspondam às suas necessidades e objetivos." (Ponte 1998, p.2).

Ao considerar um grupo de trabalho colaborativo, Fiorentini (2004) entende que é aquele em que: a participação é voluntária e os envolvidos buscam crescimento profissional e autonomia; deseja-se compartilhar saberes e experiências; há momentos informais para bate-papo e comentários sobre episódios e práticas escolares; os participantes estão abertos a críticas e têm liberdade para se expressar; não existe orientação única para as atividades. São aceitas contribuições e as participações ocorrem em diferentes níveis; as tarefas são planejadas; existe confiança e respeito mútuo; há negociação de metas e objetivos comuns, bem como comprometimento para atingi-los; há compartilhamento do significado do que realizam e aprendem no grupo; os participantes podem produzir e sistematizar conhecimentos através de textos escritos; há reciprocidade de aprendizagem.

Outros autores que investigaram sobre trabalho coletivo foram Murphy e Lick (1998). Destaca-se que esses autores trabalharam a ideia de grupo de estudo no interior de escolas norte-americanas através do projeto Whole-Faculty study groups. Mas o que é um grupo de estudos de professores? Trata-se de "um pequeno número de indivíduos trabalhando juntos para aumentar suas capacidades através de nova 
aprendizagem para o benefício dos alunos." (Murphy \& Lick, 1998, p.4).

De acordo com Murphy e Lick (1998), trabalhar em grupo não é uma ideia nova, os psicólogos sociais apontam para a potencialidade do trabalho coletivo há décadas, mas as escolas pouco usam isso em seu favor. Apesar de simples, tal ideia para os autores é poderosa: trabalhar em pequenos grupos buscando melhorar o desempenho profissional.

A Resolução de Problemas passou a ser fortemente discutida pelo NCTM, no início da década de 1980, sendo uma das recomendações para o ensino de Matemática nos Estados Unidos, naquela década. Os modos de realizar um trabalho, em sala de aula de Matemática, fundamentado na resolução de Problemas, apresentavam variações. Hatfield (1978) já apregoava três diferentes formas de trabalho com resolução de problemas, que puderam ser ainda percebidas no final da década de 1980, por Schroeder e Lester (1989), no livro do ano, Novas Direções para a Matemática Escolar Elementar. Esses últimos autores descrevem três modos de abordar a resolução de problemas:

- Teorizar sobre resolução de problemas: baseia-se no modelo de Polya (1978), ou alguma variação dele, em que são ensinados os passos que um bom resolvedor de problemas deve seguir. A Resolução de Problemas deve, nessa forma de trabalho, ser tratada como uma nova disciplina.

- Ensinar Matemática para resolver problemas: centra-se na importância de como a Matemática pode ser aplicada. Esse paradigma é denominado por Van de Walle (2001) por "ensinar-então-praticar". Nele, a aprendizagem matemática fica separada do fazer Matemática e a resolução de problemas está separada do processo de aprendizagem matemática.

- Ensinar Matemática através da resolução de problemas: O ponto de partida desse processo é a situação-problema e novo conhecimento matemático é construído durante a resolução do problema. Esse modo é visto, no início da década de 1990, como uma metodologia de ensino.

Visando a um ensino-aprendizagem acompanhado de compreensão e significado através da Resolução de Problema, Onuchic (1999), durante um Curso de Formação Continuada, elaborou um roteiro para aula que foi posteriormente ampliado (Zuffi \& Onuchic, 2007; Allevato \& Onuchic, 2009; Onuchic \& Allevato, 2011, 2014). A proposta atual consiste na organização das atividades por meio das etapas a seguir:

1- Preparação do problema: O professor deve selecionar um problema gerador visando à construção de um novo conceito, princípio ou procedimento. O conteúdo matemático requerido para a resolução do problema não deve ter sido trabalhado em sala de aula.

2- Leitura individual: $\mathrm{O}$ aluno deve receber uma cópia do problema, preferivelmente impressa para que não se distraia ou perca tempo em copiá-lo da lousa. O professor deve solicitar que ele faça uma leitura individual.

3- Leitura em conjunto: Neste momento, os alunos se reúnem em grupo e realizam a leitura do problema novamente. Se houver dificuldade no entendimento de palavras do enunciado (o que seria um problema secundário), os alunos poderão consultar o dicionário. Caso haja dificuldade em ler o problema, o professor pode auxiliar.

4- Resolução do problema: Após percorrer as etapas anteriores, em seus grupos, os alunos buscam resolver o problema. Este é um trabalho cooperativo e colaborativo em que os estudantes irão aprender uns com os outros.

5- Observar e Incentivar: O professor tem o papel de observador, mediador, incentivador da aprendizagem. Cabe ao docente possibilitar que os alunos pensem, dando-lhes um tempo adequado para suas reflexões e incentivando a troca de ideias entre os estudantes nos grupos. A postura do professor não é a daquele que passa uma atividade na lousa e permanece sentado em sua mesa, mas daquele que circula entre os grupos, e neles observa e avalia as atividades que estão ocorrendo.

O professor deve incentivar a autonomia dos alunos durante a resolução dos problemas, permitindo soluções criativas. Além disso, como interventor e questionador, o docente deve auxiliar os alunos a resolver problemas secundários. São exemplos de problemas secundários: interpretação do enunciado, notação, passagem da linguagem materna para a linguagem matemática, dificuldades nas técnicas operatórias, dentre outras.

6- Registro das resoluções na lousa: Diversas resoluções devem ser colocadas pelos grupos na lousa. Não importa se as resoluções estão certas ou erradas, mas devem constar nelas os diferentes processos realizados. É um momento muito rico, pois os alunos sentem-se envolvidos e curiosos para a resposta.

7- Plenária: Neste momento, os alunos são convidados a defender seus pontos de vista e a esclarecer suas dúvidas. Os estudantes devem discutir suas resoluções e analisar a validade de suas respostas com os colegas. O professor, nesse processo, é o mediador nas discussões e deve possibilitar a participação ativa e efetiva de todos os alunos, pois a avaliação é um processo contínuo.

8- Busca do consenso: Com o esclarecimento das dúvidas e a análise das diversas resoluções, todos buscam um consenso sobre o resultado correto.

9- Formalização do conteúdo: Após esse trabalho conjunto, cabe ao professor fazer a sistematização dos conceitos e conteúdos construídos. É importante o uso da terminologia matemática, além das definições, demonstrações e uso das propriedades adequadas ao assunto.

10- Proposição e resolução de novos problemas: Os novos problemas propostos possibilitam que o professor analise se os alunos compreenderam os elementos essenciais do conteúdo matemático aprendido, introduzido naquela aula. Além disso, o professor, por meio dessa décima etapa, pode consolidar aprendizagens construídas nas etapas anteriores, aprofundar e ampliar as compreensões sobre determinado assunto ou tópico matemático.

A palavra composta Ensino-Aprendizagem-Avaliação foi criada para expressar a ideia de que ensino e aprendizagem devem ocorrer simultaneamente e a avaliação deve estar integrada ao ensino para promover a aprendizagem. A utilização desta metodologia promove um processo "em espiral", possibilitando que o professor resgate conhecimentos prévios dos alunos, com participação ativa dos mesmos, e que possa aprofundar e ampliar suas compreensões sobre um conceito, procedimento ou conteúdo matemático.

O referido roteiro foi, no caso do presente trabalho, adaptado para a formação de professores. No grupo de estudos, foi utilizada a Metodologia de Ensino-AprendizagemAvaliação de Matemática através da Resolução de Problemas e os professores puderam ressignificar os conceitos trazidos, 
por meio de problemas, pela professora-pesquisadora e trabalhados por todos. A professora-pesquisadora assumiu a postura de uma integrante do grupo, que incentivava, orientava e também pôde aprender com o grupo.

\section{Participantes, Instrumentos, Métodos e Procedimentos}

O grupo de estudos constituiu-se por sete docentes (três professores e quatro professoras) de Matemática de uma escola pública da rede estadual de São Paulo (Brasil) e pela professora-pesquisadora. O tempo de serviço no magistério desses professores mostrou-se diversificado: um deles ministra aulas de Matemática há 23 anos, outro há 17 anos, dois deles têm 14 anos de profissão, um professor tem 13 anos de magistério, outro tem 9 e o mais jovem de profissão tem 8 anos. A fim de preservar a identidade dos participantes, os professores, neste texto, serão designados por P1, P2, P3, P4, P5, P6, P7 e a Professora Pesquisadora por PP.

Os encontros ocorreram por 15 semanas, com duração de duas horas cada. Os quatro primeiros encontros foram teóricos, com leitura e discussão de textos sobre Resolução de Problemas e os demais foram práticos, abarcando diversos conteúdos (Álgebra, Números Racionais, Medidas, Logaritmos, Geometria Analítica e Trigonometria). A direção e coordenação pedagógica da escola gostaram da iniciativa, mas não havia uma sala específica de reuniões na escola e os encontros aconteciam na sala dos professores.

Tendo como base a pergunta da pesquisa e o referencial teórico foi iniciada uma intensa reflexão sobre os dados obtidos a partir de instrumentos diversos: gravação dos encontros em áudio e vídeo, notas de campo, análise das resoluções dos problemas produzidas pelos sujeitos por escrito, análise das produções orais e discussões dos problemas propostos.

A partir dos dados coletados e cruzando essas informações com o que diz a literatura sobre os saberes docentes, foi utilizado um processo de categorização emergente-misto (Fiorentini \& Lorenzato, 2012). Desse modo, os eixos temáticos elencados a partir dessa análise foram:

- Eixo 1: A Resolução de Problemas na aprendizagem e na ressignificação dos conhecimentos matemático e didático-pedagógico na formação do professor de Matemática.

- Eixo 2: A Problematização da Resolução de Problemas nas práticas de ensinar e aprender Matemática na sala de aula.

- Eixo 3: A Metodologia de Ensino-AprendizagemAvaliação de Matemática através da Resolução de Problemas na formação do professor de Matemática.

- Eixo 4: Os grupos de estudo sobre Resolução de Problemas como espaços de aprendizagem dos professores e de futuros professores de Matemática.

\section{Resultados e Discussão}

Com relação ao eixo temático "A Resolução de Problemas na aprendizagem e na ressignificação dos conhecimentos matemático e didático-pedagógico na formação do professor de Matemática" foram selecionados encontros do grupo que apresentavam discussões e a construção ou ressignificação do conhecimento matemático na formação de professores.

Ao se trabalhar o tema Medidas na formação de professores, pretendia-se que os grupos refletissem sobre sua importância, sobre a necessidade do uso de unidades de medida e sobre como poderiam desenvolver esse tema apoiando-se na resolução de problemas.

Sobre as dificuldades encontradas no trabalho em sala de aula com o tema medidas, o grupo ressaltou que:

P6: Eu sinto dificuldade no conceito de metro. De fazer entender o que é o metro! Eu acho que o problema tá em entender o que é medir! Porque, muitas vezes, eles não sabem o que é medir, o que significa medir. Aí, se não sabe o que é medir, então não tem sentido a unidade!

PP: E o que significa medir?

P6: Comparar.

PP: Comparar o quê?

P7: Alguma coisa com uma unidade padrão de mesma natureza.

A $P P$ concluiu, juntamente com os grupos, que para se medir sempre é feita uma comparação entre uma grandeza e a unidade padronizada de mesma natureza da grandeza considerada. Essa unidade pode ser o $m m, o c m, o ~ m$ ou o $\mathrm{km}$, para comprimentos, ou o, o ou outros para medida de massa. Dependendo do que se quer medir, tem-se uma unidade apropriada para realizar essa comparação.

Problema 1

O lado de cada quadradinho da figura abaixo mede $7 \mathrm{~mm}$.

a) Qual é o perímetro da figura? E sua área quanto mede?

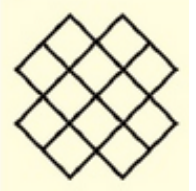

b) E se a medida do lado fosse dobrada, qual seria a medida da área?

No grupo, o professor P7 percebeu que o perímetro seria 16 vezes e a área seria. A professora $\mathrm{P} 3$ perguntou se não havia um jeito mais fácil. P7 sugeriu que se poderia pensar em "completar o quadrado", o que ficaria e depois "descontar" os cantos.

Aproveitando a ideia de P7, esse problema poderia ser resolvido acrescentando-se quatro cantos à figura original.

Assim, o lado do novo quadrado formado seria igual 4

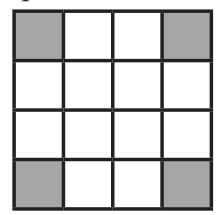

Ao calcular o perímetro, que é a soma dos lados da figura, 
ficaria:

Pode-se notar que não é preciso descontar os cantos, visto que foram adicionados $2 l$ e nos cantos quebrados também se considerava essa medida.

Para se calcular a área da figura, como cada quadradinho de lado $7 \mathrm{~mm}$ tem uma área de $49 \mathrm{~mm}^{2}$, a área desse quadrado criado seria de Para obter a área total da figura inicial, tornase necessário descontar a área de cada um dos quadradinhos acrescentado, ou seja, deve-se fazer

Ao duplicar a medida do lado, o novo quadrado "com os cantos completados" passaria a ter lado igual $56 \mathrm{~mm}$ e sua área total seria:

$$
\begin{gathered}
A_{2}=(56 \mathrm{~mm})^{2}-4 .\left(196 \mathrm{~mm}^{2}\right) \\
A_{2}=3136 \mathrm{~mm}^{2}-784 \mathrm{~mm}^{2} \\
A_{2}=2352 \mathrm{~mm}^{2}
\end{gathered}
$$

Durante a discussão do problema, o professor P1 percebeu que para calcular o perímetro sempre tinha 2 em cada lado, mas se confundiu ao contar os "cantos quebrados". Em cada um desses cantos, ao invés de acrescentar, ele estava considerando apenas e chegou que o perímetro da figura seria, o que não é correto.

Quanto ao que acontece quando se duplica a medida do lado da figura, os professores responderam:

P6: O perímetro dobra...

P7: É! O perímetro dobra [...] Se você simplesmente pensar que tem 16 faces e essa face dobra, então você vai continuar com 16 vezes a face vezes 2 .

PP: A medida, a unidade...

P7: Isso... o ladinho. Se fosse um 1 qualquer o perímetro seria 161. A partir do momento que você dobra... seria 1612 [...] Agora, é interessante que quando você coloca... se você pensar que a área... você tem 12 quadradinhos e a área é o lado ao quadrado, a hora que você dobra ... ela fica (lado 2$)^{2}$ então $1^{2} 2^{2}$. Então, independente do lado, você vai multiplicar aí por $4 . .$. que é o dobro ao quadrado.

PP: Então o que a gente conclui? Se dobrar o lado...

P6: O perímetro dobra e a área quadruplica!

Apesar de toda a discussão e cuidado com as unidades de medida, o professor P7 apresentou ao grupo uma resolução do problema em que as unidades de medida foram postas apenas nas respostas. Tal fato parece indicar que os professores estão habituados a usar as unidades de medida apenas nas respostas dos problemas, o que pode prejudicar o entendimento de seus alunos em relação ao uso de medidas.
Figura 1 - Resolução do problema pelo P7.

$$
\begin{aligned}
& P_{1}=16 \cdot 7=112 \mathrm{~mm} \\
& A_{1}=7^{2} \cdot 12=588 \mathrm{~mm}^{2} \\
& P_{2}=16 \cdot 7 \cdot 2=(16 \cdot 7) \cdot 2=2 \cdot P_{1} \\
& A_{2}=(7 \cdot 2)^{2} \cdot 12=7^{2} \cdot 4 \cdot 12=7^{2} \cdot 12 \cdot 4=4 \cdot A_{1} \\
& \Rightarrow P_{2}=2 \cdot 112=224 \mathrm{~mm}^{2} \\
& A_{2}=4 \cdot 588=2352 \mathrm{~mm}^{2}
\end{aligned}
$$

Fonte: Dados da pesquisa

O tema Medidas foi bastante motivador para a formação de professores. Novamente, conceitos simples, como o que significa medir, foram trabalhados e provocaram reflexões e ressignificações sobre o conteúdo matemático abordado. Além disso, destacou-se a necessidade de o professor de Matemática ter cuidado, durante a resolução de um problema, com o uso correto das unidades de medida. De acordo com os Parâmetros Curriculares Nacionais de Matemática (Brasil, 1998), esse cuidado auxiliaria no trabalho não só da própria Matemática, mas de outras disciplinas como a Geografia e as Ciências Naturais. Essa também é a recomendação da Base Nacional Comum Curricular (Brasil, 2018), que justifica: "As medidas quantificam grandezas do mundo físico e são fundamentais para a compreensão da realidade" (Brasil, 2018, p. 273).

Um ponto evidenciado ao analisar esses encontros referese ao saber manifestado pelos professores em exercício que se relaciona às suas salas de aula. É um conhecimento situado e construído na prática, chamado por Cochran-Smith e Lytle (1999) de conhecimento na prática. Além disso, o grupo problematizou alguns conteúdos matemáticos e algumas práticas de sala de aula, por meio da resolução de problemas, em direção à construção do que as referidas autoras chamam de conhecimento da prática

De acordo com Borges (2004, p.69), “os 'saberes da experiência' têm um papel fundamental, pois [...] a partir dos saberes da experiência, os outros conhecimentos são avaliados, julgados e utilizados no trabalho." Assim, pode-se afirmar que é pelo e no trabalho que os demais saberes profissionais serão transformados e adaptados de acordo com a realidade das situações de ensino. Por isso, a formação no local de trabalho mostrou-se positiva e vista pelos professores participantes, de acordo com P6, como "uma troca de experiências e de coisas práticas de quem conhece a realidade da escola".

No eixo temático "A problematização da resolução de problemas nas práticas de ensinar e aprender Matemática na sala de aula" a Resolução de Problemas possibilitou a problematização das práticas de ensinar e aprender Matemática.

Uma posição defendida pelos professores de Matemática participantes da pesquisa refere-se à importância da 
memorização e do treino das técnicas operatórias nas aulas. Em diversas ocasiões, que serão apresentadas nos excertos a seguir, integrantes de dois subgrupos formados entre eles manifestaram suas opiniões nessa direção.

$\mathrm{O}$ professor P5 defendeu a repetição, o treinamento da Matemática por parte dos alunos. Além disso, esse professor afirmou que "Na Matemática Moderna tinha repetição, mas se tinha resultado. Hoje nós estamos aí nessa Matemática... 'Deixa ele pensar...". Sua fala desconsiderou importantes fatores sociais e históricos da educação brasileira e ao dizer “(...) Deixa ele pensar”, P5 desconsiderou o papel do professor. O que se propõe não é deixar o aluno pensar sem orientação, mas que o professor seja o observador, mediador, organizador, interventor e incentivador desse processo de aprendizagem.

Nessa discussão, P6 destacou que a memorização, no entanto, não antecede o conceito matemático:

P6: Eu não entendo por esse lado... que o aluno não tenha que ter! Mas é que pulavam-se fases. Não se trabalhava a compreensão de que a tabuada são somas de parcelas iguais. Já ia-se direto assim que é 6 sem entender que aquilo... você tem o , que você tá aumentando. Eu acho que seria mais nesse sentido, você ter a compreensão do que seria a tabuada e, a partir do momento em que o aluno entende como a tabuada é formada, ele acaba fazendo a memorização da tabuada. Porque se ele quer saber quanto é, sei lá,... ele compreende que é 70 , ele consegue diminuir uma parcela e chegar no resultado.

A afirmação de P6 mostrando a necessidade da compreensão do conceito matemático, provocou uma negociação e problematização daquilo que os professores P7 e P5 estavam destacando. Essas formas de compreender a aprendizagem da Matemática precisam ser pensadas, já que os professores podem carregá-las sem nenhum questionamento, reproduzindo inclusive as práticas de seus antigos professores de Matemática. Um exemplo disso pode ser percebido na discussão entre os professores, durante o 10 encontro, reproduzida a seguir:

P2: Nada me tira da cabeça e que meus professores da faculdade não escutem! Que isso é falta de treino, é condicionamento! Porque você pode entender [...] mas é falta de treino!

P7: Sim...é falta de treino!

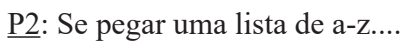

PP: Mas quantas vezes nós não fizemos isso com eles?

$[\ldots]$

P3: Não fez não! Eles não fazem...

$[\ldots]$

P2: Potência mesmo... eu lembro do meu professor..., ele deu uma lista de a-z, depois ele deu de 1 a não sei quanto...

$\underline{\mathrm{P} 3}$ : Era assim... 200 exercícios por tarde... tem que fazer!

$[\ldots]$

Apesar de toda discussão promovida nos encontros, essa concepção foi bastante enraizada em suas experiências e práticas durante anos a fio. P6, novamente, fez contrapontos e apresentou o exemplo da tabuada que, para ela, o aluno deve compreender e depois memorizar.

Ao se resgatar a Educação Matemática e as fases pelas quais passou o ensino de Matemática, de acordo com Lambdin e Walcott (2007), a ênfase no cálculo foi enfatizada na década de 1920 e muito aplicada em décadas posteriores. No entanto, a opinião revelada pelos professores e futuros professores sobre o treino no ensino de Matemática mostra que tal ideário ainda pode ser fortemente encontrado em sala de aula no Brasil hoje.

Sobre o treino nas aulas, no $15^{\circ}$ encontro, P2 ao trabalhar um problema envolvendo expressões algébricas com seus alunos de $9^{\circ}$ ano, figura 2 , relatou que a dificuldade inicial foi com o conceito de perímetro e, posteriormente, em como realizar a soma algébrica.

Figura 2 - Problema aplicado por P2 em sala de aula. Observe a figura:

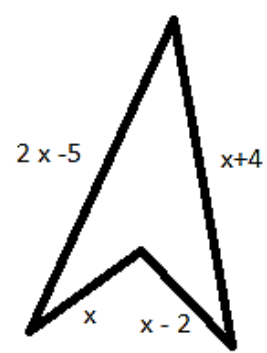

Qual é a expressão que representa o perímetro da figura? Fonte: Dados da Pesquisa

Destaca-se aqui que P2 considerou que, se o aluno sabe realizar a operação de adicionar o valor da medida dos lados da figura, ele tem o domínio conceitual. No entanto, tal episódio revela que os alunos estão acostumados a trabalhar, em sala de aula, a técnica operatória ou uma fórmula, em detrimento de um entendimento conceitual.

Ao ser questionada pela $P P$ sobre como havia sido a plenária, e se ela havia chamado alunos à lousa para exporem suas resoluções, $\mathrm{P} 2$ disse:

P2: Não! Primeiro eu queria que eles tentassem. Como a gente teve só uma aula (50 minutos), deixei os comentários para a aula seguinte...

PP: Qual será seu próximo passo, então?

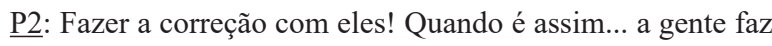
junto!

Por meio desse excerto pode-se notar que a professora ainda não conseguia deixar os alunos resolverem os problemas, sem lhes fornecer informações ou fazer a correção. Ela, apesar de ter proposto um problema, não consegue mediar e incentivar a construção do conhecimento por parte dos alunos. O próximo passo, para $\mathrm{P} 2$, seria a de ela mesma fazer a correção, não dando oportunidade de os alunos participarem de uma plenária. Essa posição mostra a dificuldade de se sair da zona de conforto e romper com antigas práticas de ensinar e de aprender Matemática.

P2 ainda faz um desabafo ao grupo: "Achei que eles iam tirar de letra... dei, fiz igual ao que meu professor fazia... de 
$a-j$, de $a-l$ pra fazer... Fazem tudo, depois você pede de novo... É! Aí que é furado que treino não é solução! [...]”. Esse trecho mostra que a professora apoiou sua prática atual de sala de aula em exemplos de práticas de seu professor da Educação Básica. Pode-se perceber a necessidade de se problematizar essas práticas, como foi possibilitado nesse grupo de estudo. P2 percebeu e revelou ao grupo que apenas treinar os alunos não apresentou um resultado satisfatório.

No eixo temático "A Metodologia de EnsinoAprendizagem-Avaliação de Matemática através da Resolução de Problemas na formação do professor de Matemática" foram apresentadas e discutidas as experiências dos professores quando tentaram implementar a referida metodologia. Destaca-se, ainda, que ela permeou os encontros dos grupos de estudo, possibilitando reflexões, discussões e ressignificações do conhecimento matemático e didáticopedagógico entre os professores.

O exemplo de prática escolhido para ser apresentado neste artigo foi o de P6. A professora trabalhou com duas classes de 6 ano do Ensino Fundamental. O objetivo de P6, motivada pelo grupo de estudo, foi o de trabalhar com os Números Racionais.

Buscando desenvolver o roteiro da Metodologia de Ensino-Aprendizagem-Avaliação de Matemática através da Resolução de Problemas, primeiramente, falou para os alunos que iriam trabalhar em grupos e que ela iria entregar dois problemas para serem discutidos. Orientou-os que eles poderiam resolver fazendo desenhos, contas ou como conseguissem, mas que deveriam chegar a um consenso no grupo, de qual seria a resposta correta. Ela dividiu, então, a turma em grupos formados por quatro alunos. P6 disse que escolheu alguns representantes para os grupos, escreveu os nomes na lousa e eles foram selecionando com quem gostariam de trabalhar. Em alguns casos a professora, não concordando, sugeriu novos agrupamentos.

Uma das observações feitas por P6 foi que "Até as crianças, que não são exemplos de alunos, na sala de aula, ficaram curiosos e tentaram resolver os problemas".

\section{O problema 1 de $\mathbf{P 6}$}

Três pizzas devem ser divididas igualmente entre cinco pessoas. Quanto de pizza cada pessoa comerá?

Um problema secundário identificado pela professora foi o de que os alunos acharam, de início, que toda pizza viria dividida em 8 partes. Desse modo, sobrariam pedaços, já que, se fossem 24 pedaços ao todo, cada um comeria 4 pedaços e sobrariam 4. Um aluno sugeriu que a divisão da pizza fosse em 16 partes, mas que essa ação não adiantaria pois também sobrariam pedaços. P6, então, esclareceu que não estava escrito que a pizza veio cortada em 8 partes e que eles poderiam cortá-las em quantas partes quisessem. Alguns grupos cortaram em 10 partes, obtendo 30 pedaços no total e distribuindo 6 pedaços por pessoa. Outro grupo dividiu cada pizza em partes diferentes. Um dos grupos dividiu cada pizza em 5 partes. Em seguida, a professora solicitou que os grupos entregassem a atividade e explicassem o que haviam feito. Para formalizar, P6 desenhou as pizzas na lousa e questionou os alunos:

P6: [...] Se cada um vai ganhar um pedaço de pizza, esse pedaço aqui... de uma pizza quanto representa? Daí eles falaram: “Ah, isso é !". Aí eu falei: Então quantos pedaços ele ganhou? "!" (Eles responderam). Aí eu chamei atenção... porque a pergunta é assim... que parte de pizza ele vai ganhar? Então ele quer saber a parte de 1 pizza, que é o que ele vai ganhar..

\section{O problema 2 de $\mathrm{P} 6$}

Jô, Pat e Cris resolveram fazer um piquenique e combinaram levar sanduíches para o almoço. Jô levou 3 sanduíches, Pat levou 2 e Cris se esqueceu do combinado e não levou nenhum. Assim, resolveram repartir os sanduíches que tinham levado igualmente entre as três, mas cobraram de Cris R $\$ 5,00$ por sua parte. Que parte dos R\$5,00 recebeu Jô? E Pat?

De acordo com P6 os alunos sentiram dificuldade para compreender este problema. Então, a professora realizou uma leitura juntamente com a sala e disse que eles deveriam decidir como os $\mathrm{R} \$ 5,00$ deveriam ser divididos entre as meninas que levaram os lanches.

$\mathrm{Na}$ plenária, a professora relatou que as respostas foram:

P6: [...] "R $\$ 2,50$ !" ... Na hora! É imediato. R $\$ 2,50$ para cada uma. Aí eu falei: Mas vocês acham justo dar $\mathrm{R} \$ 2,50$ para cada uma? Elas contribuíram com partes iguais? Elas levaram a mesma quantidade de lanches? "Ah, não!" (eles responderam). Aí foi $\mathrm{R} \$ 3,00$ para uma e $\mathrm{R} \$ 2,00$ para a outra. Isso foi a sala inteira...

Querendo resolver o problema proposto, após o trabalho em grupo de seus alunos, P6 desenhou os lanches na lousa, dividiu-os em três partes iguais, 15 partes no total. A representação do problema então, seria:
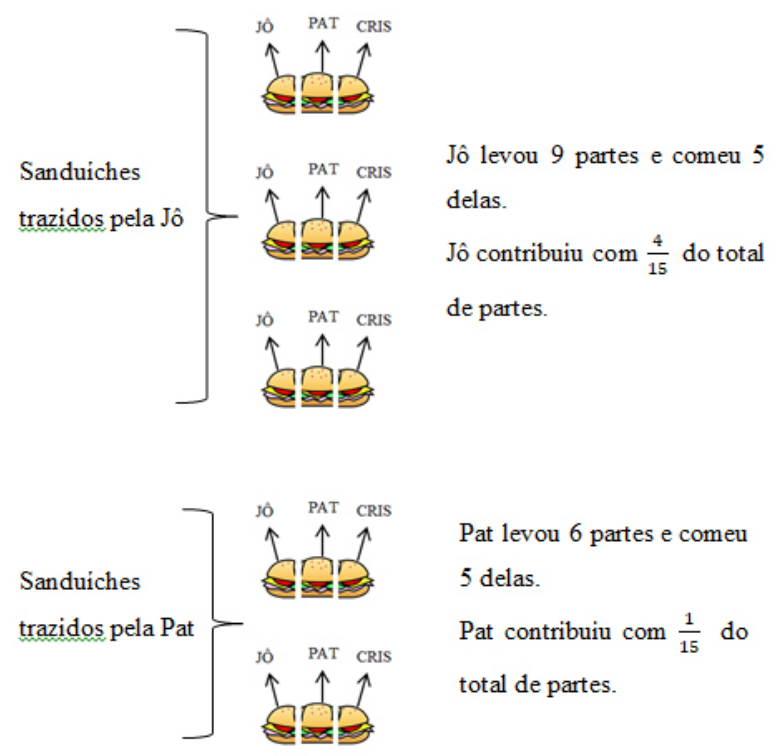

Lançando mão da representação, a P6 levou os alunos a perceberem que Cris deveria dar $\mathrm{R} \$ 4,00$ para Jô e $\mathrm{R} \$ 1,00$ para Pat.

Da mesma maneira que no problema 1, P6 nessa resolução 
conduziu os alunos no processo de resolução do problema. Essa forma de trabalho não atende a Metodologia proposta neste trabalho. A experiência de P6 mostrou que o professor pode se arriscar e que é ele quem conhece seus alunos e como pode conduzi-los. Ela criou, junto com os alunos, a ideia de equipe e, com isso, envolveu seus alunos na atividade. Possivelmente nas folhas entregues pelos grupos à professora aparecessem tentativas dos alunos buscando alternativas para a resolução do problema.

Os questionamentos e dúvidas dos alunos mostraram também que cabe ao professor trabalhar, caso haja necessidade, com a leitura e a interpretação do problema. Uma das dificuldades dos alunos ao trabalhar com problemas, estando acostumados a usar a técnica na resolução de exercícios, está na fase inicial - na leitura e na interpretação da linguagem vernácula e passagem para a linguagem matemática.

Neste terceiro eixo temático, as aprendizagens docentes ocorreram desde aspectos relacionados ao conteúdo matemático, que se refletiram nos problemas propostos, até aspectos relacionados à prática de sala de aula. Apesar das tentativas, de modo geral, os professores em exercício mostraram dificuldade em mudar suas práticas em sala de aula. Os problemas, conforme indicam os PCNs (Ministério da Educação e do Desporto, 1998), não têm desempenhado seu verdadeiro papel e que os professores tendem a trabalhar os problemas como aplicação ou fazendo cálculos com os números do enunciado. Desse modo, a atividade matemática não é explorada, os conteúdos matemáticos não são construídos, mas apenas seus resultados e técnicas. Já a BNCC (Brasil, 2018), conforme Andreatta e Allevato (2018, p.1), não traz a Resolução de Problemas explicitamente como uma metodologia de ensino, "[...] estando associada, na maioria das vezes, à aplicação de situações-problema para desenvolver habilidades, atitudes e competências desejadas". Para os autores há uma concepção, diferentemente das orientações propostas pelo $\mathrm{PCN}$, relacionada à aplicação das habilidades matemáticas com a resolução de problemas (ensinar matemática para resolver problemas).

No quarto eixo temático, "Os grupos de estudo sobre Resolução de Problemas como espaços de aprendizagem de professores e de futuros professores", por meio de depoimentos, foi apresentada a forma como os participantes da pesquisa perceberam os grupos de estudo como espaço de formação. Assim, no último encontro, solicitou-se que os professores destacassem o que acharam do trabalho promovido pelo grupo de estudo e quais contribuições foram percebidas por eles:

\section{- Aproveitamento do espaço ATPC}

P7: Eu acho assim... primeiro, você reunir por área e discutir coisas pertinentes à área, é, às vezes, muito mais produtivo do que você fazer uma reunião de ATPC só com burocracia [...] não que não seja importante, mas você pode resolver essas questões burocráticas simplesmente pregando um comunicado na sala dos professores. [...] A ideia de aproveitar o ATPC para desenvolver um grupo de estudo... eu achei excelente em primeiro lugar por conta disso...

A ATPC tem como uma de suas funções, de acordo com as orientações estaduais, a "formação continuada dos educadores, propulsor de momentos privilegiados de estudos, discussão e reflexão das propostas curriculares e melhoria da prática docente" (Comunicado Cenp, de 29 de janeiro, 2008. Nesse sentido, o grupo de estudo formado atendeu totalmente a essas finalidades.

P3 também concordou com o uso desse espaço para um grupo de estudo:

P3: E outra coisa que eu achei legal... às vezes a gente fica no ATPC lá, sem fazer nada, não fica? Acontece!... e eu acho que aqui dá pra gente trocar uma ideia, se unir... eu achei super legal essa ideia!

\section{P7: Aproveitar esse horário é ótimo!}

- Estudo da Matemática e compartilhamento de ideias e experiências

Os professores indicaram o estudo da Matemática, a leitura conjunta de textos de Educação Matemática e o compartilhamento de experiências e práticas de sala de aula como sendo algo positivo na formação de professores possibilitada pelo grupo de estudo:

$\underline{\mathrm{P} 2}$ : Mesmo para discutir conceitos, trocar experiências...

P7: [...] A gente se reunindo em grupos, querendo ou não, você acaba compartilhando determinadas experiências e isso é bom! Porque a gente precisa ter um contraponto pra saber se aquilo que você tá falando... como você faria [...] a gente começa a fazer uma avaliação também daquilo que a gente faz.. [...]

P2: E o próprio estudo da disciplina, né? Na ATPC normal a gente não estuda Matemática, a gente não faz leitura da área $[\ldots]$

P7: Na verdade, é a primeira vez que na ATPC a gente faz um grupo de estudo... vou ser sincero, desde que eu comecei a dar aula...

\section{$[\ldots]$}

P41: Pra mim... como eu não fiz Matemática... isso daqui seria o melhor projeto dentro de uma escola. Então [...] começar a ver conteúdos e conceitos que eu não vi... pra mim é interessante!

P2: Mesmo eu... fazendo Matemática... tem coisa que eu falo "Gente, eu não sei isso daqui! Eu precisava voltar a estudar..." $[\ldots]$

A análise dessa discussão entre os professores, no grupo de estudo, mostrou que é novidade para eles um trabalho desse tipo. Mesmo para P7, que dá aulas há mais de 15 anos, esse grupo de estudo foi pioneiro. Além disso, todos consideraram que o estudo do conteúdo matemático e os aspectos didático-

1 P4 tem formação inicial em Administração de Empresas e fez Complementação em Matemática. Essa formação destina-se a portadores de diploma de nível superior (Licenciatura, Bacharelado ou Curso Superior de Tecnologia), em conformidade com a Resolução $\mathrm{N}^{\mathrm{o}} 02$, de $1^{\circ}$ de Julho de 2015 , do Conselho Nacional de Educação (CNE) do Brasil e os qualifica para atuarem em sala de aula. 
pedagógicos foram necessários. Também foi ressaltada pela professora $\mathrm{P} 4$, durante o 5 encontro, ao fazer uma avaliação do grupo, a falta de trabalhos cooperativos no interior da escola: "Eu, particularmente, tô gostando da teoria... porque a maioria das coisas eu nunca vi [...] Acho que isso é o que falta numa escola, a troca!".

Por outro lado, uma dificuldade sentida por P6 é que a ATPC é um dos momentos em que ela prepara atividades e corrige provas, e sugeriu, então, que as próximas reuniões do grupo, depois dos 15 encontros iniciais, fossem quinzenais. No entanto, também ressaltou que o grupo de estudo formado foi válido, interessante e que possibilitou o compartilhamento de experiências entre os professores.

Ao fazer uma avaliação do trabalho do grupo, $\mathrm{P} 4$ ressaltou que os professores deveriam tentar levar para a sala de aula o que foi discutido, buscando transformar sua prática:

P4: Eu acho assim... isso aqui é válido! É importante! Mas eu acho que vai da consciência de cada um... porque não adianta a gente fazer a reunião aqui e sair todo mundo super feliz daqui [...] vai da consciência de cada um... se você vai entrar na sala de aula e vai tentar pelo menos dar uma aula (diferente)...

Ao analisar a fala de $\mathrm{P} 4$ pode-se notar que sua afirmação é desafiadora. Ela acredita que os professores precisam sair de suas zonas de conforto e arriscarem-se. Certamente, a mudança passa pela reflexão e isso o grupo possibilitou em todos os seus encontros. Os professores, participantes da pesquisa, foram unânimes em reconhecer a importância desses espaços de formação, desde que haja planejamento e foco nas atividades próprias da prática de ensinar e aprender Matemática. A continuidade desse trabalho e o apoio entre os pares mostra-se fundamental nesse processo dos professores de "caminhar para uma zona de risco".

De acordo com Imbernón (2011) e Mizukami et al. (2002), a escola deve ser vista como um lócus de formação, não se tratando apenas de uma mudança do local de formação, mas de um paradigma colaborativo entre os professores. Desse modo, a escola pode contribuir para o desenvolvimento profissional de seus professores, e o resultado desse processo reverte-se em benefícios para a unidade escolar e, especialmente, para os alunos.

A formação continuada promovida no grupo de estudo possibilitou que os professores repensassem sobre seus saberes docentes, por meio de um outro olhar sobre eles, como apontam Fiorentini, Nacarato e Pinto (1999, p.40):

[...] não se trata de retirar o professor de seu contexto de trabalho e transmitir-lhe uma série de teorias e modelos para serem aplicados em sala de aula mas, ao contrário, de promover momentos de reflexão, explicitação e problematização de seus saberes, crenças/concepções sobre a prática pedagógica de Matemática.

No caso dos professores de Matemática que participaram desta pesquisa, a Resolução de Problemas permeou essas discussões, possibilitando a problematização de seus saberes profissionais.

Curi (2012) considera que os docentes que ensinam
Matemática esforçam-se na busca de alternativas para a melhoria da aprendizagem de seus alunos. No entanto, de acordo com a autora, "faltam-lhes oportunidades de contatos com a pesquisa, com experiências de sucesso, com outros professores" (p. 13). Nesse sentido, para Perez (1999), é necessário que o trabalho colaborativo seja interiorizado pelo professor como forma de atuar no cotidiano.

Os grupos de estudo constituídos com professores de Matemática possibilitaram o contato com as pesquisas sobre Resolução de Problemas e com seus pares. Pode-se perceber pelo depoimento dos participantes que os grupos de estudo foram novidade, o que corrobora com as ideias de Curi (2012) no que se refere à falta de oportunidades de espaços de aprendizagem como este na formação de professores.

\section{Considerações Finais}

A formação de professores na escola, concordando com Imbernón (2011), não deve ser apenas uma mudança física do local de formação, mas refere-se ao desenvolvimento de um paradigma colaborativo entre os professores. Assim, as escolas constituir-se-iam em espaços específicos de formação, locais em que os próprios professores, mediados pelas suas necessidades e saberes, poderiam desenvolver-se profissionalmente. Além disso, esse espaço, preenchido por suas experiências e saberes, mostra-se como potencializador de reflexão e mudança de práticas em direção a um ensino de melhor qualidade.

No grupo constituído houve compartilhamento de experiências; reflexão sobre suas práticas; discussão e reflexão sobre conteúdos matemáticos; apoio entre os professores de uma mesma área; reflexões sobre o rompimento da ênfase na técnica operatória matemática em direção a uma forma de ensino que busca a compreensão das ideias matemáticas.

Quanto ao estudo e uso da Metodologia de EnsinoAprendizagem-Avaliação de Matemática através da resolução de problemas, em sala de aula, pode-se destacar que o crivo da experiência foi importante. Ao conhecerem a realidade da escola e de seus alunos, os professores demonstraram ter gostado das discussões, mas revelaram algumas concepções em relação ao ensino de Matemática, sendo que uma delas seria a de que o aluno aprende Matemática por meio do treino das técnicas operatórias. Problematizar essas concepções prévias mostrou-se um processo desafiador. O caso de P2, que trabalhou listas de exercícios sobre equações do 1 grau com seus alunos do 9 ano e quando, no bimestre seguinte, percebeu que eles não haviam compreendido o conteúdo, foi um exemplo que possibilitou essa problematização no grupo de estudo. Dessa forma, foi possível desequilibrar esses professores, fazendo-os refletir sobre suas práticas e sobre o próprio conhecimento matemático de cada um.

À guisa de conclusão, pode-se destacar que a referida metodologia, trabalhada em grupos de estudo, mostrou-se um recurso poderoso não apenas para a sala de aula mas, também, para a formação de professores. A própria essência desta Metodologia exige reflexão e construção coletiva de 
conhecimentos.

\section{Referências}

Allevato, N. S. G.\& Onuchic, L. R. (2009). Ensinando Matemática na sala de aula através da resolução de problemas. Boletim Gepem. n. 55, 122-154.

Andreatta, C. \& Allevato, N. S. G. (2018). A Resolução de Problemas nos documentos de

orientação curricular oficiais da Educação Básica Brasileira. In Seminário Internacional de Pesquisa em Educação Matemática. (pp. 1-12). Foz do Iguaçu, Brasil. Disponível em:

http://www.sbemparana.com.br/eventos/index.php/SIPEM/VII_ SIPEM/paper/view/466/498.

Borges, C. M. F. (2004). O professor da educação básica e seus saberes profissionais. Araraquara: JM Editora.

Brasil. Ministério da Educação. (2018). Base Nacional Comum Curricular. Brasília: MEC/SEF.

Brasil. Ministério da Educação e do Desporto. (1998). Parâmetros Curriculares Nacionais: Matemática (5 a 8séries). Brasília: $\mathrm{MEC} / \mathrm{SEF}$.

Cochran-Smith, M. \& Lytle, S. L. (1999). Relationships of Knowledge and Practice: Teacher Learning in Communities. Review of Research in Education, 24, 249-305.

Comunicado da Coordenadoria de Estudos e Normas Pedagógicas de 29 de janeiro, 2008. Estado de São Paulo.

Curi, E. (2012). Contribuições de um grupo colaborativo no desenvolvimento profissional de seus participantes. In E. Curi \& J. C. P. Nascimento. Educação Matemática: grupos colaborativos, mitos e práticas. (pp.13-53). São Paulo: Terracota.

Fiorentini, D. (2004). Pesquisar práticas colaborativas ou pesquisar colaborativamente? In M. C. Borba, \& J. L. Araújo. Pesquisa qualitativa em Educação Matemática. (pp. 47-76). Belo Horizonte: Autêntica.

Fiorentini, D., Nacarato, A. M., \& Pinto, R. A. (1999). Saberes da experiência docente em Matemática e Educação Continuada. Quadrante, 8, 33-60.

Fiorentini, D \& Lorenzato, S. (2012). Investigação em Educação Matemática: percursos teóricos e metodológicos. Campinas: Autores Associados.

Hatfield, L. L. (1978). Heuristical emphasis in the instruction of mathematical problem solving: Rationales and research. In L. L. Hatfield \& D. A. Bradbard (Org.). Mathematical Problem Solving: papers from a research workshop. Columbus: ERIC.

Justulin, A. M. (2014). A formação de professores de Matemática no contexto da Resolução de Problemas. (Tese de Doutorado em Educação Matemática). Instituto de Geociências e Ciências Extas, Universidade Estadual Paulista Julio de Mesquita Filho, Rio Claro.

Imbernón, F. (2011). Formação docente e profissional: formar-se para a mudança e a incerteza. São Paulo: Cortez.
Lambdin, D.V., \& Walcott, C. (2007). Changes through the years: Connections between psychological learning theories and the school mathematics curriculum. In W. G. Martin. The Learning of Mathematics. (pp. 03-25). Reston, VA: NCTM.

Mizukami, M. G. N., Reali, A. M. M. R., Reyes, C. R., Martucci, E. M., Lima, E. F., Tancredi, R. M. S. P. \& Mell, R. R. (2002). Escola e aprendizagem da docência: processos de investigação e formação. São Carlos: EdUFSCar.

Morais, R. S. \& Justulin, A. M. (2016). Resolução de Problemas - Entre o tudo e o nada: possíveis articulações. Revista de Matemática, ensino e cultura (REMATEC). (pp. 91-108). 11, n. 21.

Murphy, C. U.; Lick, D. W. (1998). Whole-faculty Study Groups: A Powerful Way to Change Schools and Enhance Learning. Corwin: Thousand Oaks.

Onuchic, L. R. (1999). Ensino-aprendizagem de Matemática através da resolução de Problemas. In M. A. V. Bicudo (Org.). Pesquisa em Educação Matemática: concepções e perspectivas. (pp. 199-218). São Paulo: Editora da UNESP.

Onuchic, L. R.\& Allevato, N. S. G. (2011). Pesquisa em Resolução de Problemas: caminhos, avanços e novas perspectivas. Bolema - Boletim de Educação Matemática. v.25, n. 41, 7398.

Onuchic, L. R., \& Allevato, N. S. G. (2014). EnsinoAprendizagem-Avaliação de Matemática: por que através da Resolução de Problemas? In L. R. Onuchic, N. S. G. Allevato, F. C. H. Noguti \& A. M. Justulin (Org.). Resolução de Problemas: Teoria e Prática. São Paulo: Paco Editora.

Perez. G. (1999). Formação de professores de Matemática sob a perspectiva do desenvolvimento profissional. In M. A. V. Bicudo (Org.). Pesquisa em Educação Matemática: concepções e perspectivas. (pp. 263-282). São Paulo: UNESP.

Polya, G. A arte de resolver problemas. (1978). São Paulo: Interciência.

Ponte, J. P. (1998). Da formação ao desenvolvimento profissional. Actas do ProfMat 98 (pp. 27-44). Lisboa: APM.

Schroeder, T. L.\& Lester, F. K., JR. (1989). Developing understanding in mathematics via problem solving. In P. R. Trafton \& A. P. Shulte (Eds.). New directions for elementary school mathematics. (pp. 31-42). Reston: NCTM.

Tardif, M. (2010). Saberes Docentes e formação profissional. Petrópolis: Vozes.

Van de Walle, J. A. (2001). Elementary and Middle School Mathematics. New York: Longman.

Zuffi, E. M.\& Onuchic, L. R. (2007) O Ensino-Aprendizagem de Matemática através da Resolução de Problemas e os Processos Cognitivos Superiores. Revista Iberoamericana de Educación Matematica, n. 11, 79-97. 